\title{
LiF by atomic layer deposition-Made easy
}

Cite as: J. Vac. Sci. Technol. A 38, 050401 (2020); https://doi.org/10.1116/6.0000314

Submitted: 08 May 2020. Accepted: 17 July 2020 . Published Online: 06 August 2020

(iD) Julie N. Kvalvik, Kristian B. Kvamme, Kjetil Almaas, (D) Amund Ruud, (D) Henrik H. Sønsteby, and (D) Ola Nilsen
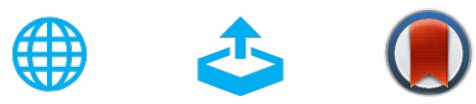

View Online

\section{ARTICLES YOU MAY BE INTERESTED IN}

Consistency and reproducibility in atomic layer deposition

Journal of Vacuum Science \& Technology A 38, 020804 (2020); https://

doi.org/10.1116/1.5140603

tert-butoxides as precursors for atomic layer deposition of alkali metal containing thin films Journal of Vacuum Science \& Technology A 38, 060804 (2020); https:// doi.org/10.1116/6.0000589

Understanding chemical and physical mechanisms in atomic layer deposition

The Journal of Chemical Physics 152, 040902 (2020); https://doi.org/10.1063/1.5133390

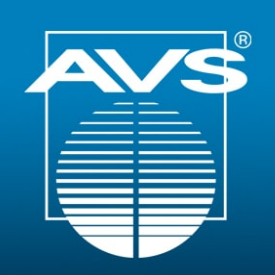

\section{Advance your science-and} career as a member of

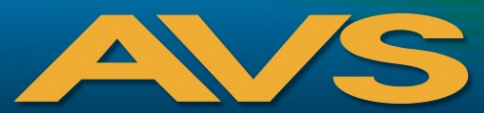

\section{LEARN MORE}




\title{
LiF by atomic layer deposition-Made easy
}

Cite as: J. Vac. Sci. Technol. A 38, 050401 (2020); doi: $10.1116 / 6.0000314$

Submitted: 8 May 2020. Accepted: 17 July 2020 .

Published Online: 6 August 2020

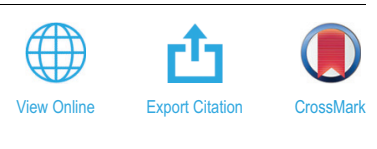

Julie N. Kvalvik, ${ }^{1}$ (D) Kristian B. Kvamme, ${ }^{7}$ Kjetil Almaas, ${ }^{7}$ Amund Ruud, ${ }^{1,2}$ (D) Henrik H. Sønsteby, ${ }^{2}$ and Ola Nilsen ${ }^{1, a)}$ (D)

\author{
AFFILIATIONS \\ ${ }^{1}$ Department of Chemistry, Centre for Materials Science and Nanotechnology, University of Oslo, Sem Sælandsvei 26, \\ Oslo 0371, Norway \\ ${ }^{2}$ Nordic Institute of Dental Materials, Sognsveien 70 A, Oslo 0855, Norway
}

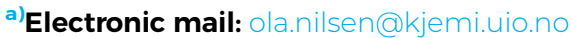

\begin{abstract}
Lithium fluoride (LiF) is an integral part of UV optics. Recently, it has also gained attention for its role in the solid-electrolyte interphase on the anode of lithium-ion batteries. Atomic layer deposition (ALD) is the preferred tool for synthesizing conformal and pin-hole free LiF thin films, especially on high aspect ratio structures. Present routes to deposit LiF by ALD are based on HF or HF-pyridine as the fluorine source, requiring strict safety precautions. Other routes involve $\mathrm{TiF}_{4}$ or $\mathrm{WF}_{6}$, resulting in inclusions of $\mathrm{Ti}$ or $\mathrm{W}$ impurities in the resulting films. Herein, we present a new route to deposit $\mathrm{LiF}$ by $\mathrm{ALD}$, using lithium tert-butoxide $\left(\mathrm{LiO}{ }^{\mathrm{t}} \mathrm{Bu}\right)$ and $\mathrm{NH}_{4} \mathrm{~F}$ as precursors. The process yields uniform films over a broad temperature range $\left(150-300^{\circ} \mathrm{C}\right)$, with a growth per cycle of $50.9 \mathrm{pm} / \mathrm{cycle}\left(225^{\circ} \mathrm{C}\right)$. The films are free from any nitrogen contamination from the $\mathrm{NH}_{4} \mathrm{~F}$ precursor. This process provides a facile route for high purity LiF thin films with the use of less harmful precursor chemistry.
\end{abstract}

Published under license by AVS. https://doi.org/10.1116/6.0000314

\section{INTRODUCTION}

Lithium fluoride (LiF) is a large bandgap material with applications within bulk heterojunction polymers $^{1-3}$ and perovskite photovoltaics, ${ }^{4-6}$ and is found in the solid electrolyte interphase (SEI) in lithium-ion batteries. ${ }^{7}$ A strategy to enhance battery performance is to preform, and thus control, SEIs. ${ }^{8}$ Preforming LiF coatings as artificial SEIs has been shown to reduce Mn-dissolution in manganite based cathodes and improve cycling stability on both lithium metal and silicon anodes. 9 Among a range of viable techniques for the deposition of $\mathrm{LiF}$, atomic layer deposition (ALD) excels as an ideal method for coating uniform, thin, and pinholefree LiF films for batteries and optics. ALD also provides the possibility of conformal coatings of high aspect ratio substrates, an essential feature for fabricating devices such as $3 \mathrm{D}$ batteries. ${ }^{10-14}$ ALD is already in use in the kiloton scale within the battery ${ }^{15}$ and solar industries, ${ }^{16}$ although for the deposition of various oxides, such as $\mathrm{Al}_{2} \mathrm{O}_{3}$. A handful of routes for deposition of $\mathrm{LiF}$ by ALD has been reported and summarized in Table I.

Using $\mathrm{LiO}^{t} \mathrm{Bu}$ and hexafluoroacetylacetone was also attempted recently, but this yielded porous $\mathrm{LiF}-\mathrm{CF}_{\mathrm{x}}$ hybrid films. ${ }^{9}$ Several of the established routes use either HF or HF-pyridine as the fluorine source, requiring strict safety precautions. Moreover, using $\mathrm{TiF}_{4}$ or $\mathrm{WF}_{6}$ as the fluorine source leads to traces of $\mathrm{Ti}$ or $\mathrm{W}$ in the resulting films. Here, we extend the toolbox of ALD LiF-processes by depositing phase pure, crystalline thin films, combining $\mathrm{LiO}^{\mathrm{t}} \mathrm{Bu}$ and $\mathrm{NH}_{4} \mathrm{~F}$, which was introduced as an ALD-precursor already in 1994.

\section{EXPERIMENT}

Thin films were deposited in an F-120 Sat ALD reactor (ASM Microchemistry). $\mathrm{LiO}^{\mathrm{t}} \mathrm{Bu}$ (Sigma Aldrich, 97\%) and $\mathrm{NH}_{4} \mathrm{~F}$ (Sigma Aldrich, 99.99\%) were used as precursors delivered from open boats inside the reactor held at 130 and $95^{\circ} \mathrm{C}$, respectively. Pulsing/purging times were $5 \mathrm{~s} / 5 \mathrm{~s}$ and $7 \mathrm{~s} / 3 \mathrm{~s}$ for $\mathrm{LiO}^{t} \mathrm{Bu}$ and $\mathrm{NH}_{4} \mathrm{~F}$, respectively. Standard pulsing and purging times are used unless otherwise stated. $\mathrm{N}_{2}$ was used as a purging gas, supplied from gas cylinders (Praxair, 99.999\%), passing through a Mykrolis purifier and kept at a primary flow rate of $300 \mathrm{~cm}^{3} \mathrm{~min}^{-1}$. A background pressure of $4.5 \pm 1 \mathrm{mbar}$ was maintained throughout all depositions. Unless otherwise stated, 1000 ALD cycles are employed for each of the depositions. The films were deposited on $1 \times 1 \mathrm{~cm}^{2} \mathrm{Si}(100)$ substrates with a $\sim 2 \mathrm{~nm}$ thick native oxide layer. 
TABLE I. List of reported ALD-processes used to deposit LiF and their key characteristics.

\begin{tabular}{|c|c|c|c|c|c|}
\hline Li-source & F- source & GPC (pm per cycle) & Deposition temperature $\left({ }^{\circ} \mathrm{C}\right)$ & Crystal structure & Reference \\
\hline $\mathrm{LiO}^{\mathrm{t}} \mathrm{Bu}$ & HF-pyridine & 88 at $150^{\circ} \mathrm{C}$ & 150 & Rock salt & 22 \\
\hline LiHMDS & HF-pyridine & 58 at $150^{\circ} \mathrm{C}$ & $125-250$ & Rock salt & 18 \\
\hline $\operatorname{Li}($ thd $)$ & $\mathrm{TiF}_{4}$ & 148 at $250^{\circ} \mathrm{C}$ & $250-350$ & Rock salt & 24 \\
\hline LiHMDS & Anhydrous HF & 150 at $150^{\circ} \mathrm{C}$ & $100-250$ & $\mathrm{n} / \mathrm{a}$ & 25 \\
\hline $\mathrm{LiO}^{t} \mathrm{Bu}$ & $\mathrm{WF}_{6}$ & $\mathrm{n} / \mathrm{a}$ & $150-300$ & $\mathrm{n} / \mathrm{a}$ & 26 \\
\hline $\mathrm{LiO}^{\mathrm{t}} \mathrm{Bu}$ & $\mathrm{MoF}_{6}$ & 260 at $150{ }^{\circ} \mathrm{C}$ & $150-300$ & Rock salt above $150^{\circ} \mathrm{C}$ & 26 \\
\hline $\mathrm{LiO}^{t} \mathrm{Bu}$ & $\mathrm{TiF}_{4}$ & 50 at $250^{\circ} \mathrm{C}$ & $200-300$ & Rock salt & 9,27 \\
\hline $\mathrm{LiO}^{t} \mathrm{Bu}$ & Hhfac & $\mathrm{n} / \mathrm{a}$ & 220 & $\mathrm{n} / \mathrm{a}$ & 9 \\
\hline $\mathrm{LiO}^{t} \mathrm{Bu}$ & $\mathrm{NH}_{4} \mathrm{~F}$ & 55 at $250^{\circ} \mathrm{C}$ & $150-300$ & Rock salt & This work \\
\hline
\end{tabular}

The substrates were cleaned with ethanol and blown dry with pressurized air prior to deposition. Growth dynamics were measured in situ at $225^{\circ} \mathrm{C}$ by a quartz crystal microbalance (QCM) using an Eon-LT monitor (Colnatec) and a self-made crystal holder. An AT-cut gold-plated quartz crystal (Inficon SPC-1157-G1) with a $6 \mathrm{MHz}$ nominal frequency was used. The presented QCM data show an average over 16 consecutive ALD cycles for improved statistics. The density of a LiF film was measured ex situ by x-ray reflectivity (XRR), with the extracted density and thickness used for converting the response of the QCM crystal to mass gain per unit area of the film. A known LiF deposition sequence was added several places in the QCM campaign as an internal standard to accommodate for variations in surface texture, and thus evolution of surface area of the QCM crystal during the campaign. A PANalytical Empyrean diffractometer with a $\mathrm{CuKa}_{1}$ source, a parallel beam mirror with a $1 / 32^{\circ}$ divergence slit, a $0.27^{\circ}$ parallel plate collimator, $0.04 \mathrm{rad}$ soller slits, and an automatic nickel attenuator was used for the XRR measurements. The XRR data were modeled and analyzed using the accompanying X'Pert Reflectivity software. The thickness and refractive indices at $\lambda=632.8 \mathrm{~nm}$ for the thin films were investigated with spectroscopic ellipsometry using an alpha-SE (J.A. Woollam). The collected SE data were fitted successfully with a Cauchy model using the CompleteEASE software.

$\mathrm{LiF}$ thin films were characterized with respect to composition, crystal structure, and morphology. X-ray spectroscopy (XPS) was performed with a Thermo Scientific Theta Probe Angle-Resolved XPS system, equipped with a standard $\mathrm{Al} \mathrm{K} \alpha$ source $(\mathrm{h} v=1486.6 \mathrm{eV})$. Pass-energies of 200 and $60 \mathrm{eV}$ were employed for survey scans and detailed scans, respectively. The resulting data were treated using the Thermo Scientific Avantage software suite. X-ray diffraction (XRD) was carried out to investigate the crystal structure of the obtained samples, using a Bruker D8 Discovery Diffractometer, with a $\mathrm{CuKa}_{1}$ source and a $\mathrm{Ge}(111)$ monochromator in a traditional Bragg-Brentano geometry.

Selected samples were measured by synchrotron XRD at BM01 at ESRF (Grenoble, France) for mapping a large portion of the reciprocal space and characterizing the angular scattering distribution of the $\mathrm{LiF}$ crystallites. The beamline employed a wavelength of $0.69705 \AA$, and a Dectris Pilatus $2 \mathrm{M}$ detector. Morphology was investigated using a Park Systems XE-70 atomic force microscope (AFM) with a CONTSCR tip in contact mode. It was further investigated by a HITACHI SU 8230 scanning electron microscope (SEM) with a cold cathode field emission gun using an acceleration voltage of $5.0 \mathrm{kV}$, a beam current of $5 \mu \mathrm{A}$, and a working distance of $3.3 \mathrm{~mm}$.

\section{RESULTS AND DISCUSSION}

The first step when establishing the $\mathrm{LiO}^{t} \mathrm{Bu}+\mathrm{NH}_{4} \mathrm{~F}$ process for the deposition of LiF by ALD, was to perform an in situ QCM experiment to determine if the process is ALD compatible (i.e., exhibiting saturative growth). The experiment was also used to determine the mass gain per cycle, Fig. 1, and appropriate pulsing and purging parameters, Fig. 2. Net mass gain per cycle was $10.5 \mathrm{ng} / \mathrm{cm}^{2}$ with a mass gain of $34.0 \mathrm{ng} / \mathrm{cm}^{2}$ during the $\mathrm{LiO}^{\mathrm{t}} \mathrm{Bu}$ pulse and a mass loss of $23.5 \mathrm{ng} / \mathrm{cm}^{2}$ during the $\mathrm{NH}_{4} \mathrm{~F}$ pulse.

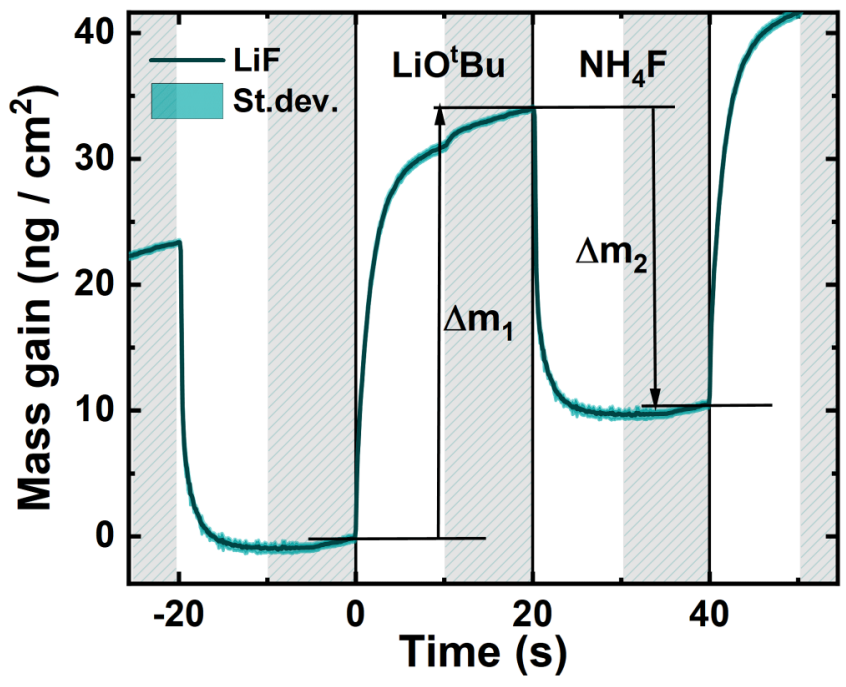

FIG. 1. Mass variation $\left(\mathrm{ng} / \mathrm{cm}^{2}\right)$ during one cycle of $\mathrm{LiO}{ }^{t} \mathrm{Bu}$ and $\mathrm{NH}_{4} \mathrm{~F}$ at $225^{\circ} \mathrm{C}$ as measured by in situ QCM. The QCM crystal was placed in the front of the reaction chamber. The green area denotes the standard deviation of the average of 16 cycles. Light gray shaded areas correspond to the inert gas purging steps. All pulses and purges were $10 \mathrm{~s}$. 


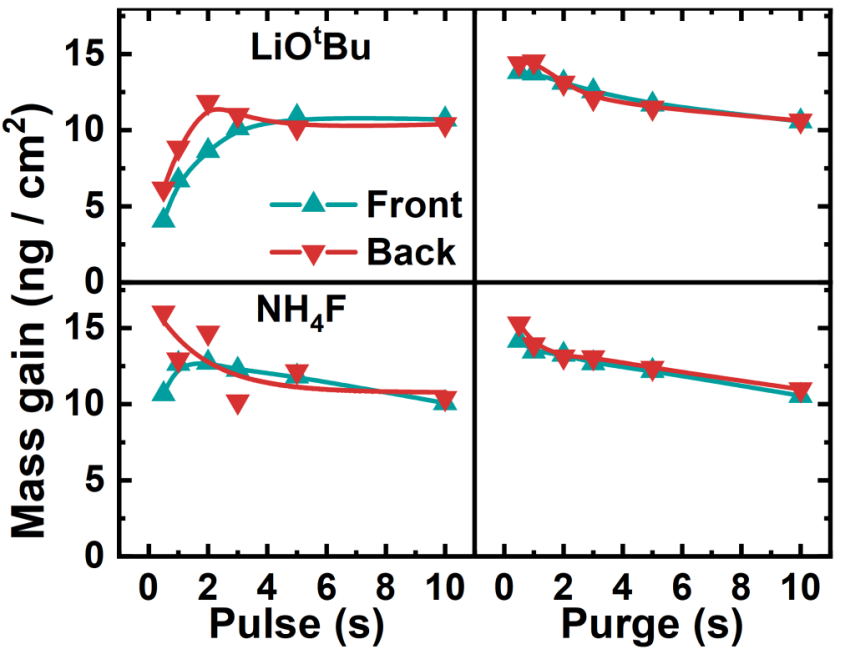

FIG. 2. Mass gain vs pulse and purge parameters investigated by $\mathrm{QCM}$ for the $\mathrm{LiO} \mathrm{Bu}^{t}+\mathrm{NH}_{4} \mathrm{~F}$ process. All other pulse and purge parameters where kept at $10 \mathrm{~s}$. The deposition temperature was $225^{\circ} \mathrm{C}$. Front and back refer to the placement of the sample in the chamber over $7.5 \mathrm{~cm}$ relative to the flow direction. Spline functions are included as a guide for the eye.

We observe a significant mass gain during the $\mathrm{LiO}^{t} \mathrm{Bu}$ pulse, followed by an almost as large mass reduction during the $\mathrm{NH}_{4} \mathrm{~F}$ pulse (Fig. 1). Mass gain per cycle is similar to that reported for the LiHMDS + HF-pyridine process at $12 \mathrm{ng} / \mathrm{cm}^{2}$ at $150{ }^{\circ} \mathrm{C} .{ }^{18}$ Suggested chemical reactions for the $\mathrm{LiO}^{t} \mathrm{Bu}$ and $\mathrm{NH}_{4} \mathrm{~F}$ pulses are summarized in Eqs. (1) and (2). We have used $\mathrm{NH}_{4} \mathrm{~F}$ as a more safely

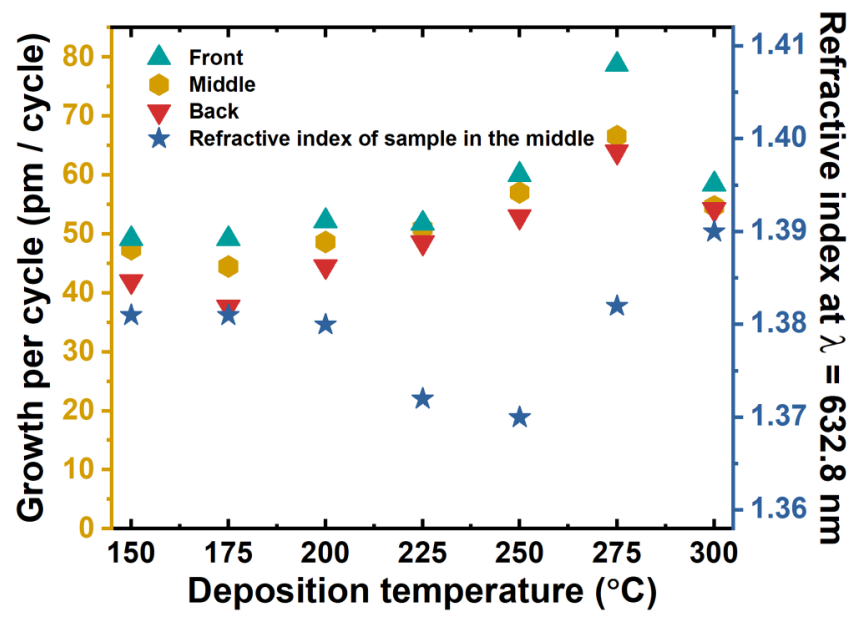

FIG. 3. Growth rate per cycle (left y axis) and refractive index at $\lambda=632.8 \mathrm{~nm}$ (right $y$ axis) as a function of deposition temperature for the $\mathrm{LiO}{ }^{t} \mathrm{Bu}+\mathrm{NH}_{4} \mathrm{~F}$ process, obtained with spectroscopic ellipsometry. Front, middle, and back refer to the placement of the sample in the chamber over $7.5 \mathrm{~cm}$ relative to the flow direction.

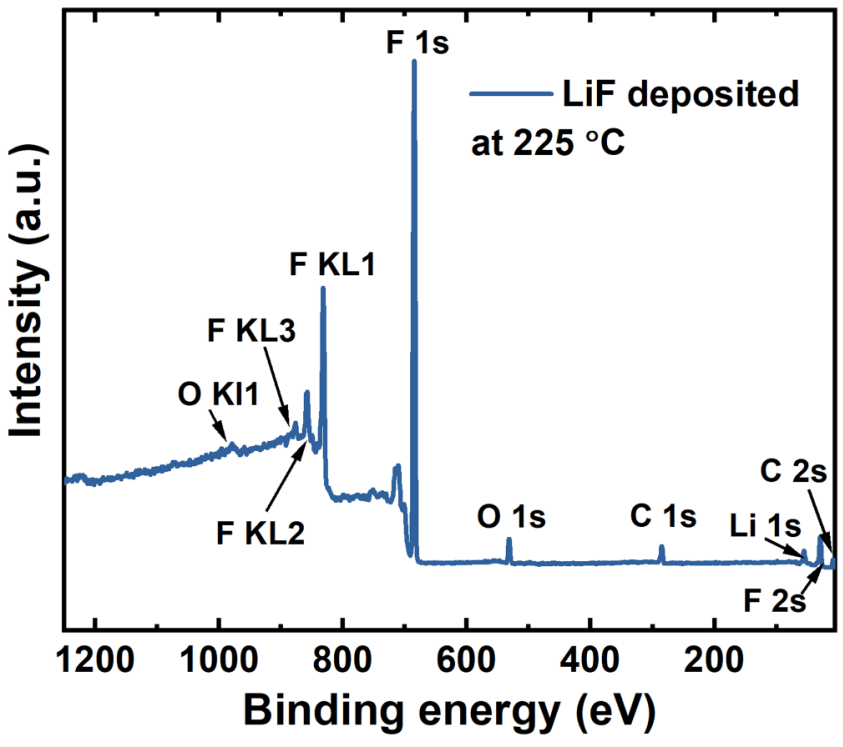

FIG. 4. XPS survey scan of an LiF sample deposited at $225^{\circ} \mathrm{C}$.

manageable source for $\mathrm{HF}$, as $\mathrm{NH}_{4} \mathrm{~F}$ is known to decompose into $\mathrm{NH}_{3}$ and $\mathrm{HF}$ upon sublimation. Therefore only HF is considered in the proposed reaction scheme. ${ }^{19}$ * denotes surface species and it should be further noted that $\mathrm{LiF}$ is a highly ionic structure where individual charges are distributed over many neighboring atoms,

$$
\mathrm{LiF}^{\star}(\mathrm{s})+\mathrm{LiO}^{t} \mathrm{Bu}(\mathrm{g}) \rightarrow \mathrm{Li}-\mathrm{F}-\mathrm{LiO}^{t} \mathrm{Bu}^{\star}(\mathrm{s}) \quad \Delta \mathrm{m}_{1},
$$

$$
\mathrm{Li}-\mathrm{F}-\mathrm{LiO}^{t} \mathrm{Bu}^{*}(\mathrm{~s})+\mathrm{HF}(\mathrm{g}) \rightarrow \mathrm{LiF}^{*}(\mathrm{~s})+{ }^{t} \mathrm{BuOH}(\mathrm{g}) \quad \Delta \mathrm{m}_{2} .
$$

The net mass gain ratio from one cycle $\left(\Delta \mathrm{m}_{1} / \Delta \mathrm{m}_{2}\right)$ is 1.45 (Fig. 1). This is in good agreement with the suggested reaction mechanisms [Eqs. (1) and (2)], with a calculated net mass gain ratio of 1.49. Future work, taking advantage of, e.g., in situ quadrupole mass spectrometry or similar techniques, could verify that tertbutanol is indeed the only by-product of this reaction and also detect $\mathrm{NH}_{3}$.

The $\mathrm{LiO}^{t} \mathrm{Bu}$ pulse saturated after about $5 \mathrm{~s}$, and this was used as the pulsing time for $\mathrm{LiO}^{t} \mathrm{Bu}$ in further investigations (Fig. 2). A $2 \mathrm{~s} \mathrm{NH}_{4} \mathrm{~F}$ pulse should be sufficient (Fig. 2). In practice, however,

TABLE II. Composition of an LiF sample deposited at $225^{\circ} \mathrm{C}$ as measured by XPS.

\begin{tabular}{cc}
\hline \hline Compound & Atomic \% \\
\hline $\mathrm{Li}$ & 52.5 \\
$\mathrm{~F}$ & 40.1 \\
$\mathrm{C}$ & 4.7 \\
$\mathrm{O}$ & 2.7 \\
\hline
\end{tabular}




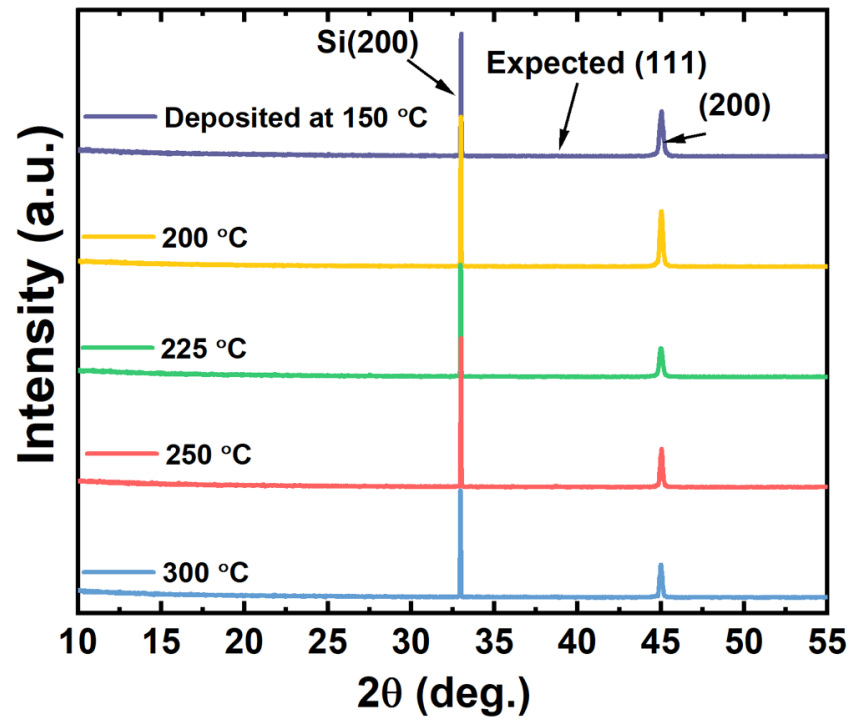

FIG. 5. XRD of LiF thin films deposited at $150,200,225,250$, and $300^{\circ} \mathrm{C}$. The (200) reflection from LiF and the $\mathrm{Si}(200)$ substrate reflection are marked.

this resulted in large gradients and a $7 \mathrm{~s} \mathrm{NH}_{4} \mathrm{~F}$ pulse was necessary to obtain uniform films.

After establishing pulse and purge parameters for the $\mathrm{LiF}$ process, growth per cycle (GPC) and refractive index were investigated as a function of deposition temperature (Fig. 3). The GPC gradually increases with temperature. We believe that the sample at $275^{\circ} \mathrm{C}$ follows an increasing trend, while the sample at $300^{\circ} \mathrm{C}$ shows deviations resembling initial decomposition or similar. We have several samples deposited at $300^{\circ} \mathrm{C}$ confirming the lowered growth rate. The refractive index has a minimum at $250^{\circ} \mathrm{C}$ but is close to the reported value of 1.391 at $300^{\circ} \mathrm{C}$, although we see a deviating GPC trend at this temperature. ${ }^{20}$ The growth rate of our process is comparable to that of LiHMDS + HF-pyridine and
$\mathrm{LiO}^{t} \mathrm{Bu}+\mathrm{TiF}_{4}$ processes, but significantly lower than the rest, where $\mathrm{LiO}^{t} \mathrm{Bu}+\mathrm{MoF}_{6}$ has the highest growth rate at $260 \mathrm{pm}$ per cycle. The low growth rate for our LiF process is not a limitation for its use as surface coating of battery materials, as such films are typically in the subnanometer to the nanometer scale.

Chemical composition and state were further characterized by XPS. Quantification of lithium by XPS is inherently difficult, but a high-resolution survey spectrum was collected to attempt an elemental analysis (Fig. 4 and Table II). See supplementary material ${ }^{21}$ for detailed XPS scans. The study points toward the formation of LiF, with a slight over-stoichiometry of lithium. This can be explained by the presence of carbon and oxygen, which is probably present as $\mathrm{Li}_{2} \mathrm{CO}_{3}$. Using $\mathrm{LiO}^{t} \mathrm{Bu}$ is known to result in small amounts of carbon contamination. ${ }^{22}$ However, since native SEIs already consist of lithium carbonates, ${ }^{18}$ a small amount of $\mathrm{Li}_{2} \mathrm{CO}_{3}$ in the LiF coating is believed to be unproblematic for use in controlling SEI formation. Some of the carbon and oxygen are also believed to stem from $-\mathrm{C}=\mathrm{O}$ surface species. It is worth noting that that depth analysis is not applicable for lithium-containing films since the etching ions tend to push lithium toward the substrate-film interface. Also take notice that no nitrogen is observed, consistent with the known decomposition of $\mathrm{NH}_{4} \mathrm{~F}$ into $\mathrm{NH}_{3}$ and HF. Time-of-flight elastic recoil detection analysis could, in the future, be used to obtain a depth profile and better understanding of the film composition (including hydrogen).

The crystallinity of the films was investigated by specular XRD (Fig. 5), in addition to synchrotron XRD for reciprocal space mapping, see supplementary material. ${ }^{21}$ Specular XRD suggests growth with preferred orientation, whereas the reciprocal space map shows a large in-plane broadening. All investigated films have a (200)-orientation throughout the deposited temperature range $\left(150-300^{\circ} \mathrm{C}\right)$. The expected (111) reflection, which should have around $75 \%$ of the intensity of the most intense (200)reflection (COD No. 1831351), is absent. Expected reflections from $\mathrm{LiF}$ at a higher $2 \theta$ angle are masked by the $\mathrm{Si}(100)$ substrate reflection in the investigated range.

Investigation of the surface morphology with SEM and AFM is not in agreement with a fully oriented sample (Fig. 6). The micrographs reveal a polycrystalline surface consisting of triangular and
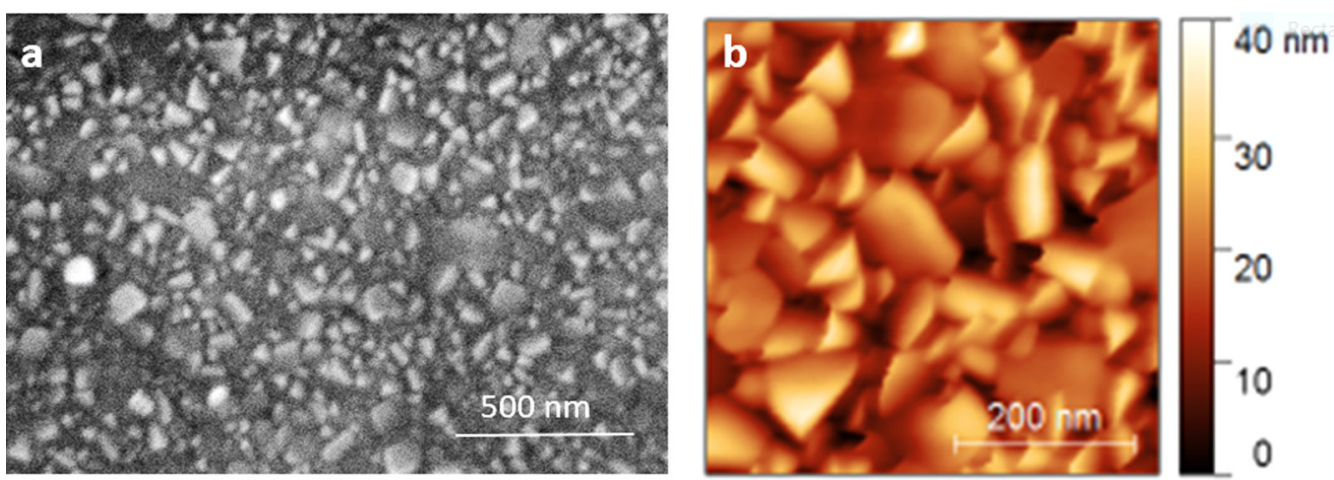

FIG. 6. SEM [(a), left] and AFM [(b), right] micrographs of a $53 \mathrm{~nm}$ thick LiF thin film deposited at $225^{\circ} \mathrm{C}$. 
square-shaped crystallites, with sizes around $50-100 \mathrm{~nm}$. This is comparable to the film thickness of $53 \mathrm{~nm}$. The RMS roughness is estimated at $6.2 \mathrm{~nm}$ from the AFM micrograph. Triangular crystallites correspond to a growth in the (111)-direction, whereas square crystallites correspond to an increase in the (200)-direction. ${ }^{23}$

The lack of the (111)-reflection (Fig. 5) is most likely caused by the low scattering power of $\mathrm{LiF}$.

\section{CONCLUSION}

In the current work, we show a viable route for deposition of $\mathrm{LiF}$ by ALD using $\mathrm{LiO}^{t} \mathrm{Bu}$ and $\mathrm{NH}_{4} \mathrm{~F}$. This process is stable in the temperature range of $150-300{ }^{\circ} \mathrm{C}$, with a GPC of $50.9 \mathrm{pm} / \mathrm{cycle}$ and a mass gain per cycle of $10.5 \mathrm{ng} / \mathrm{cm}^{2}$ cycle at $225^{\circ} \mathrm{C}$. The films are nitrogen-free as measured by XPS but with a possible slight over-stoichiometry of $\mathrm{Li}$ and minor carbon contamination. Although conventional Bragg-Brentano and synchrotron XRD suggest (200)-oriented LiF films, both AFM and SEM studies reveal square and triangular crystallites on the surface, indicating random growth.

\section{ACKNOWLEDGMENTS}

The authors would like to thank the Research Council of Norway for financing this work through the TRALALALA project (No. 244087, Julie N. Kvalvik), RIDSEM project (No. 272253, Henrik H. Sønsteby), Nano-MILIB project (No. 143732, Amund Ruud) and SOLIB project (No. 262387, Kristian B. Kvamme). Moreover, the authors would like to thank Kristian Weibye for assistance with XPS measurements.

\section{REFERENCES}

${ }^{1}$ E. Ahlswede, J. Hanisch, and M. Powalla, Appl. Phys. Lett. 90, 163504 (2007).

${ }^{2}$ D. Gao, M. G. Helander, Z.-B. Wang, D. P. Puzzo, M. T. Greiner, and Z.-H. Lu, Adv. Mater. 22, 5404 (2010).

${ }^{3}$ L. Lu, T. Xu, W. Chen, E. S. Landry, and L. Yu, Nat. Photonics 8, 716 (2014).

${ }^{4}$ X. Liu, M. Lei, Y. Zhou, B. Song, and Y. Li, Appl. Phys. Lett. 107, 063901 (2015).
${ }^{5}$ J. Seo, S. Park, Y. C. Kim, N. J. Jeon, J. H. Noh, S. C. Yoon, and S. I. Seok, Energy Environ. Sci. 7, 2642 (2014).

${ }^{6}$ K. Sun, J. Chang, F. H. Isikgor, P. Li, and J. Ouyang, Nanoscale 7, 896 (2015).

${ }^{7}$ N. Schulz, R. Hausbrand, C. Wittich, L. Dimesso, and W. Jaegermann, J. Electrochem. Soc. 165, A833 (2018).

${ }^{8}$ P. Verma, P. Maire, and P. Novák, Electrochim. Acta 55, 6332 (2010).

${ }^{9}$ O. Tiurin, N. Solomatin, M. Auinat, and Y. Ein-Eli, J. Power Sources 448, 227373 (2020).

${ }^{10}$ Y. S. Jung, A. S. Cavanagh, A. C. Dillon, M. D. Groner, S. M. George, and S.-H. Lee, J. Electrochem. Soc. 157, A75 (2010).

${ }^{11}$ Y. S. Jung, A. S. Cavanagh, L. A. Riley, S.-H. Kang, A. C. Dillon, M. D. Groner, S. M. George, and S.-H. Lee, Adv. Mater. 22, 2172 (2010).

${ }^{12}$ H. C. M. Knoops, M. E. Donders, M. C. M. van de Sanden, P. H. L. Notten, and W. M. M. Kessels, J. Vac. Sci. Technol. A 30, 010801 (2012).

${ }^{13}$ C. Marichy, M. Bechelany, and N. Pinna, Adv. Mater. 24, 1017 (2012).

${ }^{14}$ C. Zhu, K. Han, D. Geng, H. Ye, and X. Meng, Electrochim. Acta 251, 710 (2017).

${ }^{15}$ D. M. King, A. Dameron, P. Lichty, and J. Trevey, Low-Cost Encapsulation of Silicon-Based Nanopowders Final Report (Forge Nano, Louisville, CO, 2018).

${ }^{16}$ M. Hossain, K. Khoo, X. Cui, G. Poduval, T. Zhang, X. Li, W. Li, and B. Hoex, "Atomic layer deposition enabling higher efficiency solar cells: A review," Nano Mater. Sci. (in press) (2020).

${ }^{17} \mathrm{M}$. Ylilammi and T. Ranta-Aho, J. Electrochem. Soc. 141, 1278 (1994).

${ }^{18}$ L. Younghee, P. Daniela, M. C. Andrew, S. Y. Matthias, J. L. Se-Hee, and G. Steven, "Atomic layer deposition of LiF and lithium ion conducting (AlF3) $(\mathrm{LiF}) \mathrm{x}$ alloys using trimethylaluminum, lithium hexamethyldisilazide and hydrogen fluoride," ChemRxiv 12 (2017).

${ }^{19}$ E. G. Rakov and E. I. Mel'nichenko, Russ. Chem. Rev. 53, 851 (1984).

${ }^{20}$ H. H. Li, J. Phys. Chem. Ref. Data 5, 329 (1976).

${ }^{\mathbf{2 1}}$ See supplementary material at https://doi.org/10.1116/6.0000314 for synchrotronXRD and detailed XPS scans of a LiF film deposited at $225^{\circ} \mathrm{C}$.

${ }^{22}$ L. Chen et al., ACS Appl. Mater. Interfaces 10, 26972 (2018).

${ }^{23}$ O. Nilsen, O. B. Karlsen, A. Kjekshus, and H. Fjellvåg, Thin Solid Films 515, 4538 (2007).

${ }^{\mathbf{2 4}}$ M. Mäntymäki, J. Hämäläinen, E. Puukilainen, F. Munnik, M. Ritala, and M. Leskelä, Chem. Vap. Deposition 19, 111 (2013).

${ }^{25}$ J. Hennessy and S. Nikzad, Inorganics 6, 46 (2018).

${ }^{26}$ M. Mäntymaki, M. Ritala, and, M. Leskalä, Coatings 8, 227 (2018).

${ }^{27}$ J. Xie et al., ACS Nano 11, 7019 (2017). 